\title{
Learners' Preferences of iBook Features for Academic Writing
}

\author{
Farah Diana Mohd. Farid, Adelina Asmawi \\ University of Malaya, Malaysia
}

\begin{abstract}
This study presents undergraduate learners' favourite iBook features in learning Academic Writing. Today, many undergraduate learners are struggling, especially in Academic Writing course and other soft skills required in higher education institutions. This resulted in increased drop out rates due to the problems of low student achievement, boredom and alienation in the classroom [8]. These issues are present among undergraduate learners in this study. Therefore, in the present study, an iBook for Academic Writing has been identified to maximize students' engagement and learning potential in the classroom. This research applied a qualitative approach by using Graphics Prompted Interview (GPI). GPI uses personal ecological data gathered before the interview to stimulate discussion during the meeting [10]. The researchers selected three undergraduate learners who had completed their Academic Writing course in their previous semester, within a university in Malaysia. The learners were prompted with graphics of iBook features and then were interviewed on the most appealing features to be included in an iBook for Academic Writing. Results of the study indicated that Interactive Galleries, Scrolling Sidebar, Media, Chapter Review and HTML Modules are the most appealing features in learning Academic Writing using iBook. Findings also showed that students significantly favoured these iBook features, for more fun learning journey, and also to facilitate their learning in Academic Writing.
\end{abstract}

\section{Introduction}

Academic writing plays a critical role in socializing students into the discourse of subjects and disciplines in universities. However, with the massification of higher education, many students, especially those in many Malaysian more higher education institutes, are struggling to maintain academic writing standards that are acceptable in tertiary education. This has increased the demand for academic development

programs as a viable strategy to enhance the academic writing skills and other soft skills required by students [7]. Academic writing has always played a significant and central role for students all over the world. As Academic Writing is a compulsory course to pass among undergraduate students, this means the need for more references and resources for an academic writing course. Realizing this, the emerging assistive technologies such as electronic books can be employed in the curriculum as a form of differentiated instruction [6]. It is crucial to look into the creation of something similar to the learning of Academic Writing course. In the present study, iBook is identified as a potential instructional technology for students to learn Academic Writing. iBook through Apple's iPad is potential to engage students in what they are learning in the classroom to the real world [3].

Thus, this article discusses undergraduate students' preferences in learning Academic Writing using iBook in a Malaysian university. It highlights the significant preferences of students in learning Academic Writing using iBook, such as more engaging learning.

\section{Research Problem}

This study involved Foundation students at one of the private universities in Malaysia, established since early 2016, here onwards, 'Lotus University'. This university is a branch university from Mainland China, which expanded its campus in Malaysia. It is the first overseas campus sufficiently established by a renowned Chinese University with a campus of her own. In this university, there are two Foundation studies programs: Foundation in Science and Foundation in Arts and Social Sciences. Introduction to Academic Writing is a compulsory course to be taken by all Foundation students in their first semester as a prerequisite to enter the second semester. However, from conversing with most of the Foundation students at Lotus University, it was found that they face 
many difficulties in completing their research report write up, leading to low marks or even failure for the course. These are based on the recent course results from the faculty that show students' low carry marks in their assessments and in the final examination. It was found that they face various challenges in academic writing, and the course is known as a 'killer subject'. On another note, these university students are actively engaged and updated with the use of online technology, particularly the use of iPhone and ipad. Hence, looking at the issues and what the learning trend is, language instruction at the university level now requires a multilayered learning environment that goes beyond the traditional classroom lecture, one which is accessible twenty-four hours a day, seven days a week. Thus, smartphones, tablets and laptops should be ideal platforms to teach Academic Writing to the university students to obtain both active and engaging learning. This study, therefore, embarks on the following objective:

1) To investigate learners' most preferred iBook features in learning Academic Writing using iBook.

\section{Review of Related Literature}

In Malaysia, academic writing is a course that undergraduate students must pass in order to graduate. This course carries at least a minimum of four (4) credit hours depending on each university's requirement, which is a big chunk of their Cumulative Grade Point Average (CGPA). In preparation for the course, students face difficulties in writing an academic paper. This is seen across most universities in Malaysia and abroad, more so for ESL students. Presently, many ESL students at tertiary level are challenged when writing [9], are unable to write critically, are disinterested in writing, and have a poor attitude towards writing [13]. Lack of students' engagement in the classroom also has resulted in lack of in-depth content in student writings and dull presentation of essays, thus leading to low grades in their Academic Writing course.

Recently, academic dropout rates have increased due to the problems of low student achievement, boredom and alienation in classrooms [8]. This is true for many tertiarylevel students in Malaysia too. According to Burkett [2], students perceived education as boring or disaffecting, in which they try to get by with as little effort as possible. Studies find steep declines in students' motivation across different levels of study. Hence, engagement is perceived as the solution to these signs of student alienation and lack of motivation [8]. Undergraduate students in current universities are mostly dominated by Generation $\mathrm{Z}$. Generation Z born between year 1995 to 2012, are also known as "Digital Natives". They are born into a world facing widespread use of electronic gadgets and digital technologies like the Internet and social networking sites. They are characterized as tech savvy, globally connected (in the virtual world), flexible and smarter, and tolerant of diverse cultures [15]. In a study by Rothman [14], it was discovered that 'Digital Natives' needs fast delivery of content with complete graphics. They are kinesthetic, experiential, hands on learners who prefer to learn by doing rather than being told what to do or by reading texts. Therefore, it is imperative that teachers increase their computer technology use to deliver content [17].

Based on a preliminary study among the Foundation students in Lotus University, majority of these students prefer to learn Academic Writing through computer technology. They are digitally literate with most, owning an iPhone and and iPad. This is in line with the literature where the vision for educational technology that is currently promoted by education leaders, policymakers, and business and community members, foresees technology's incorporation into all aspects of the educational environment [16].

In 2012, Apple introduced a computer program called iBook Author that allows anyone with a Mac computer to author an iBook through using the provided templates. iBook Author is a user-friendly program free for Mac users. The iBook and iBook Author offer an innovative way for students to explore and learn about the world. It is interactive, potentially sensitive to learner accessibility with features like text-to-speech and highlighting of critical information [12].

Not only does iBook Author enable digital books to be developed, it also includes several interactive components. Some of these components allow users to swipe screen through pictures, watch videos, connect to websites, create and review quizzes, and interact with $3 \mathrm{D}$ graphics. From an education perspective, iBook Author allows the author to have ownership of the ibook created. Besides, the iBook can be shared free of charge to Apple devices and updated as frequently as possible (Apple, 2017).

Hence, the researchers identified iBook as the 
potential piece of computer technology to promote learning of Academic Writing specifically through exploration of these students' iBook feature preferences to overcome Academic Writing challenges. Furthermore, the online learning environment of an iBook may be enhanced through features such as video and audio, interactivity, or note taking. iBook Author allows for the inclusion of enhanced contents that stimulate interactive and immersive learning. The feature that sets iBook Author apart from other software is the possibility of adding a series of interactive objects, to enhance the reading and learning experience. There are nine different modifiable default widgets in the program: Gallery, Media, Review, Keynote, Interactive Image, 3D, Scrolling Sidebar, PopOver, and HTML [1]. Students could watch videos within their iBook, answer questions with immediate feedback, and explore 3D models, all at the touch of their fingers on their tablets, smart phones or laptops.

According to Meeker and $\mathrm{Wu}$ [11], the Apple iPad was identified as a potential piece of technology that can personalize and individualize instructional environments through the use of iBook to enhance students' engagement in Academic Writing.

Therefore, an iBook for Academic Writing has been identified to be a potential application of computer technology to maximize students' learning potential for this study.

\section{Methodology}

This research was conducted through a qualitative study, to investigate the most preferred iBook features in learning Academic Writing using iBook. Through a qualitative study method, the researcher had the opportunity to observe and bridge a closer relationship with the participants, communicate with the participants as well collect data. Thus, Merriam (1998) clarifies that the main criterion to use a qualitative method is when the concern of understanding the phenomenon understudy is to explore the perspective of the participants and not the researchers.

The method used in this study was Graphic Prompted Interview (GPI). In this study, in-depth semi structured interviews were conducted with three Foundation students in order to elicit their preferences of iBook features to learn Academic Writing using iBook. GPI uses personal ecological data gathered before the interview to stimulate discussion during the meeting [10].

In this study, the researcher showed nine sets of different features generated by iBook Author. There are nine various modifiable default features in the program: Gallery, Media, Review, Keynote, Interactive Image, 3D, Scrolling Sidebar, Popover, and HTML [1]. The interviews, which were conducted one-to-one with the students, used these graphic features of iBook, as prompts to stimulate their visual and auditory senses. According to Kwasnicka, Dombrowski, Whote, and Sniehotta [10], using graphics in GPIs could stimulate visual and auditory senses, enhance memory, and prompt rich narratives anchored in participants' experiences during the interview session. The researchers showed the features of iBook one by one and explained to the participants the functions of each feature. This also allowed prompt rich narratives on iBook features. After prompts were shown, participants had to choose the features that they preferred to be in a potential iBook for Academic Writing.

\section{Data Analysis}

Data analyses for the present study were adapted from Creswell [5] as well as Creswell and Clark [4]. A procedure was used for analysis of students' graphic prompted Focus Group Interview data. The data were transcribed first. Then the coding of the data was carried out. The codes were grouped into themes (or categories), interrelating themes (or categories) or abstracting smaller sets of themes. The researcher did thematic analysis for identifying, analyzing, and reporting patterns (themes) within the data. This involved organizing, distributing, and describing the data set in detail and interpreting various aspects of the data. The themes that captured the relevant data from the interview transcripts to answer the research questions and those that represent the patterned responses within the data set were created [4], [5].

Additionally, according to David and Sutton (2004), one of the strengths of Graphic Prompted Interview is data on non-verbal cues such as facial expressions and gestures can be recorded. For GPI, therefore, students' non-verbal cues, such as facial expressions were observed during the interview.

\section{Result and Discussions}

Based on the one-to-one graphic prompted 
interviews with the students, five preferred features emerged for an interactive iBook for Academic Writing. The features are Interactive Galleries, Scrolling Sidebar, Media, Chapter Review and HTML Modules. Figure 1 shows the preferred features, which emerged from the analysis of the results of the one-toone graphic prompted interviews with the students.

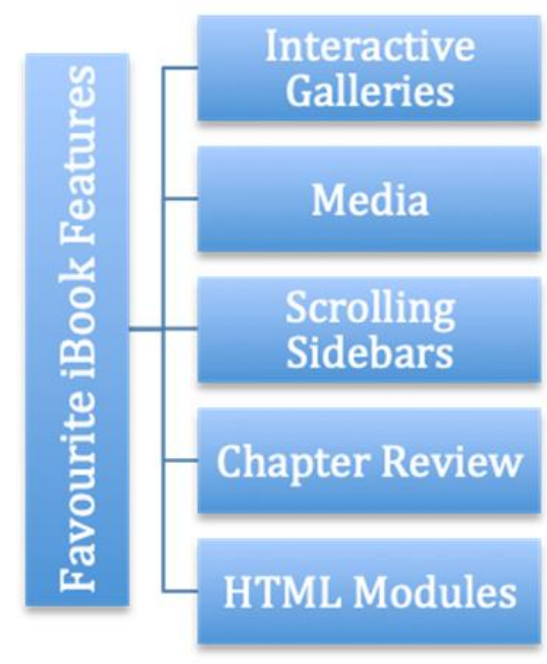

Figure 1. Favourite iBook Features

The results revealed that the respondents preferred to have Interactive Galleries, Media, Scrolling Sidebars, Chapter Review, and HTML Modules in learning Academic Writing using iBook. In this present study, students expressed their frustration on their Academic Writing subject as one of the most 'unexciting' subjects. The lecture delivery method for Academic Writing course is mainly through PowerPoint, and by reading lengthy and thick books in the class. They felt disengaged in the classroom and thought that the learning approaches by lecturers should be more engaging and exciting. Hence, students suggested using computer technology and multimedia in their lectures.

Respondents preferred the Interactive Galleries to receive step-by-step guidance in completing their academic writing. They want to have different types of essays and various styles of citation in Interactive Galleries. They enjoyed scrolling through the entire collection of pictures in the galleries. This is in line with the official page of Apple iBook Author's (2017) statement that readers can swipe through an entire collection of interactive photos and captions with a finger, instead of seeing just one image on the page.

Next, respondents preferred Media in iBook features in learning Academic Writing. Respondents preferred to use this feature in Methodology and Conclusion chapters to provide accessibility and memory recall. This finding is similar to Grimshaw (2007), who states that rich multimedia features such as audio narration and animations embedded into digital books, facilitate readers' understanding of what is read.

The third preference is Scrolling Sidebar feature. Respondents suggested using this feature too because it enables the provision of extra information on the subject matter and acts as a guide in reading iBook. Encheff (2013) states that iBook helps a learner to develop a better understanding of concepts because they have the freedom to explore a topic further through a variety of digital mediasuch as scrolling sidebars.

The fourth preference is Chapter Reviews feature. In the context of the present study, the respondents suggested having Chapter Reviews to gain more practices and to retest their comprehension in each unit. This finding is similar to the study conducted by Bodrova and Leong (2012) that students were reported to like the step-by-step solution provided when they answered the questions incorrectly. They also enjoyed the instant feedback to determine if they were solving problems correctly.

Lastly, HTML Modules was also listed among the favourite iBook features of the respondents. Students preferred to have HTML Modules in their Academic Writing iBook to obtain extra resources, save time, and as an interactive platform for lecturers and students. According to Lake (2012), iBook offers great resources through HTML Modules with plenty opportunities to revisit videos, review task instructions, and to scroll through models of written work at the students' own pace.

\section{Conclusion}

The present paper highlights various iBook features, which are deemed vital in learning Academic Writing. The most preferred features to learn Academic Writing are Interactive Galleries, Media, Scrolling Sidebars, Chapter Review, and HTML Modules. These features are suggested to provide more engagement for students in learning Academic Writing. The layout of iBook for Academic Writing course content is seen as crucial to satisfy the needs of tertiary-level undergraduate students in their academic writing to enhance their learning 
engagement in the course and to guide them in writing techniques. A higher engagement in academic writing course would potentially lead to improvement in students' writing ability.

Furthermore, students preferred to have Interactive Galleries to access more resources for essays samples and citations. They also preferred to have scrolling sidebars to obtain extra information and as a reading guide. Students were also found eager to experience beautiful features through media as it improves accessibility and memory recall. Chapter Reviews are also preferred as they get to have more practices and simple quizzes on their comprehension at the end of each topic. Lastly, HTML modules are preferred by the students to receive extra resources. This is because it is perceived to be time-saving and enables students and lecturers to access interactive discussions applications.

These findings could serve as a model for developing an iBook for Academic Writing. It is hoped that this study will provide more understanding of a new, revolutionized learning tool to create and publish an iBook for undergraduate students' Academic Writing. The results of this study show that students have interest in the iBook. Hence, the development of an iBook for Academic Writing should be worked on, all in the hope that students who are facing problems in Academic Writing would benefit from this technology. Additionally, further studies should be carried out to determine the effectiveness of this iBook among the Foundation students in the context of the Malaysian or other universities.

\section{Acknowledgements}

We owe special thanks to our family for their support in completing this research. Our gratitude also goes to the research site university for granting us the opportunity to conduct the research. We would like to thank all the departments and staff of the university who have helped us in the process of completing our research. Not to forget, the Foundation students who volunteered to be a part of this research, for their full cooperation and insightful comments.

\section{References}

[1] Alberizzi, V. L. (2013). iBooks in the classroom: Creating digital tools for learning Italian in a Japanese university.Retrieved from https://conference.pixelonli ne.net/ICT4LL2013/common/download/Paper_pdf/22

\section{0- ITL41-FPAlberizzi-ICT2013.pdf}

[2] Burkett, E. (2002). Another planet: A year in the life of a suburban high school. New York: Harper Collins.

[3] Bloemsma, M. S. (2013). Student engagement, $21^{\text {st }}$ century skills, and how the iPad is (Doctoral dissertation, University of California). Retrieved from https://search.proquest.com/docview/1415894557

[4] Creswell, J. W., \& Plano Clark, V. L. (2007). Designing and conducting mixed methods research. Thousand Oaks,

CA: Sage

[5] Creswell, J. W. (2005). Educational research: Planning, conducting and evaluating quantitative and qualitative research (2nd ed.). Upper Saddle River, NJ: Pearson Education.

[6] Edyburn, D. L. (2007). Technology-enhanced reading performance: Defining a research agenda. Reading Research Quarterly, 42(1), 146-152.

[7] Fernsten, L., \& Reda, M. (2011). Helping students meet the challenges of academic writing. Teaching in Higher Education, 16(2), 171-182.

[8] Fredricks, J. A., Blumenfeld, P. C., \& Paris, A. (2004). School engagement: Potential of the concept: State of the evidence. Review of Educational Research, 74, 59-119.

[9] Ismail, N., Maulan, S., \& Hasan, N. H. (2008). The impact of teacher feedback on ESL students' writing performance. Academic Journal of Social Studies, $8(1), 45-54$.

[10] Kwasnicka, D., Dombrowski, S. U., White, M., \& Sniehotta, F. (2015). Theoretical explanations for maintenance of behaviour change: A systematic review of behaviour theories. Health Psychology Review.

[11] Meeker, M., \& Wu, L. (2013, May). Internet trends. Paper presented at D11 Conference, Ranchos PalosVerdes, California.

[12] Meltzer, L., \& Krishnan, K. (2007). Executive function difficulties and learning disabilities: Understandings and misunderstandings.

[13] Osman, K., \& Bakar, N. A. (2012). Educational computer games for Malaysian classrooms: Issues and challenges. Asian Social Science, 8(11), 75.

[14] Rothman, D. (2014). A Tsunami of Learners Called Generation Z. Maryland Public Safety Online Journal, 1(1).

[15] Singh, A. (2014). Challenges and issues of Generation Z. IOSR Journal of Business and 
Management (IOSRJBM), 59-63.

[16] Shapley, P. (2000). On-line education to develop complex reasoning skills in organic chemistry. Journal of Asynchronous Learning Networks, 4(2).

[17] Steinweg, S. B., Williams, S. C., \& Stapleton, J. N. (2010). Faculty use of tablet PCs in Teacher Education and K-12 settings. TechTrends: Linking Research and Practice to Improve Learning, 54(3), 5461. 